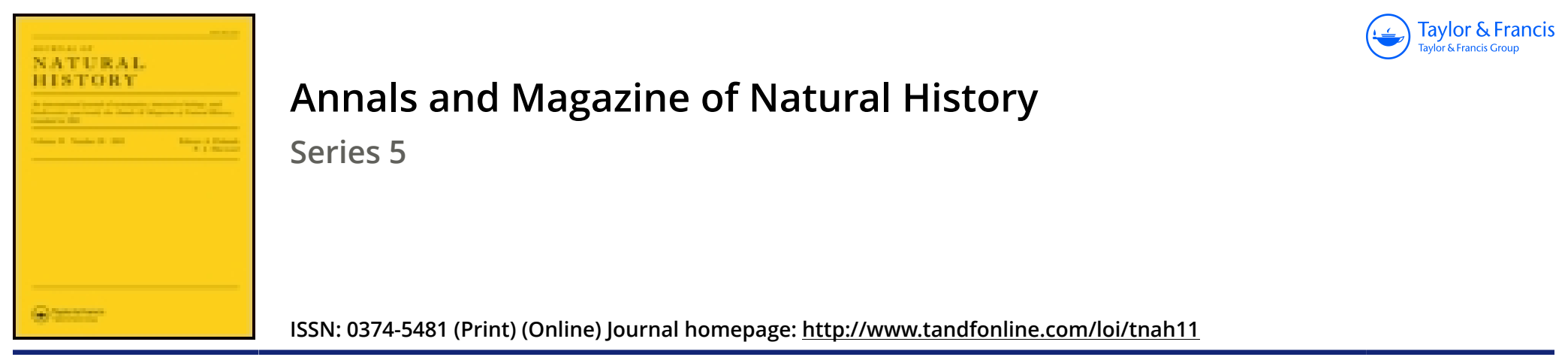

\title{
XLII.-On Stromatopora dartingtoniensis, n. sp. with tabulation in the larger branches of the astrorhiza
}

\section{H.J. Carter F.R.S.}

To cite this article: H.J. Carter F.R.S. (1880) XLII._On Stromatopora dartingtoniensis, n. sp. with tabulation in the larger branches of the astrorhiza , Annals and Magazine of Natural History, 6:35, 339-347, DOI: 10.1080/00222938009458951

To link to this article: http://dx.doi.org/10.1080/00222938009458951

曲 Published online: 07 Oct 2009.

Submit your article to this journal $\pi$

Џll Article views: 3

Q View related articles $₫$

7 Citing articles: 2 View citing articles 
(fig. 2, A), prove, beyond a doubt, that the canaliculi are entirely confined to the walls separating contiguous tubes, whether these be the proper zoœcia or the cancelli.

So far as I have seen, no " tabulæ," or but an occasional one, seem to be developed in the outer thickened portion of the tubes; but it is often possible to recognize the delicate radiating spines or "septa," which are so well displayed in tangential sections. Lastly, owing to the unequal thickening of the walls of the tubes, it is not uncommon for the longitudinal section of their cavities to assume a beaded appearance, though this is not constant, and, when present, varies much in amount.

[To be continued.]

XLII.On Stromatopora dartingtoniensis, n. $s p$. with Tabulation in the Larger Branches of the Astrorhiza. By. H. J. Carter, F.R.S. \&c.

\section{[Plate XVIII.]}

IN 1878 I made the following statement, viz. :-_" Thus in all essential points the structure of Caunopora placenta was the same as that of Millepora alcicornis," \&c. ("Annals,' vol. ii. p. 313). I also stated that, in Millepora alcicornis, "the axial [structure], which in the transverse fracture only appears to be a cribriform surface, is now [in the opposite direction] found to be composed of longitudinal tubes in juxtaposition, more or less interrupted by tabulæ, and more or less pierced with holes by which they communicate with each other" ibid. p. 308). In 1879 I found that neither of these statements was tenable, but that the tubes of Caunopora placenta belonged to a separate organism, and that the "axial structure "was Fuvosites Forbesii (not gothlandicus, as first stated), over which the Caunopora had grown.

This year (1880) an article by Dr. F. Roemer has appeared in the 'Geological Magazine' for the month of August, in which the author states (p. 345) that "Caunopora of Phillips is not a good genus, but is founded on masses of Stromatopora which are perforated by vertical tubes not essentially belonging to Stromatopora," which tubes Dr. Roemer considers a form of Aulopora repens, having previously noticed what he published in 1844, viz. "that Caunopora placenta of Phillips was nothing else than Stromatopora concentrica" (p. 344) ; now, however, he adds, "My own observations confirm entirely the statement that the 

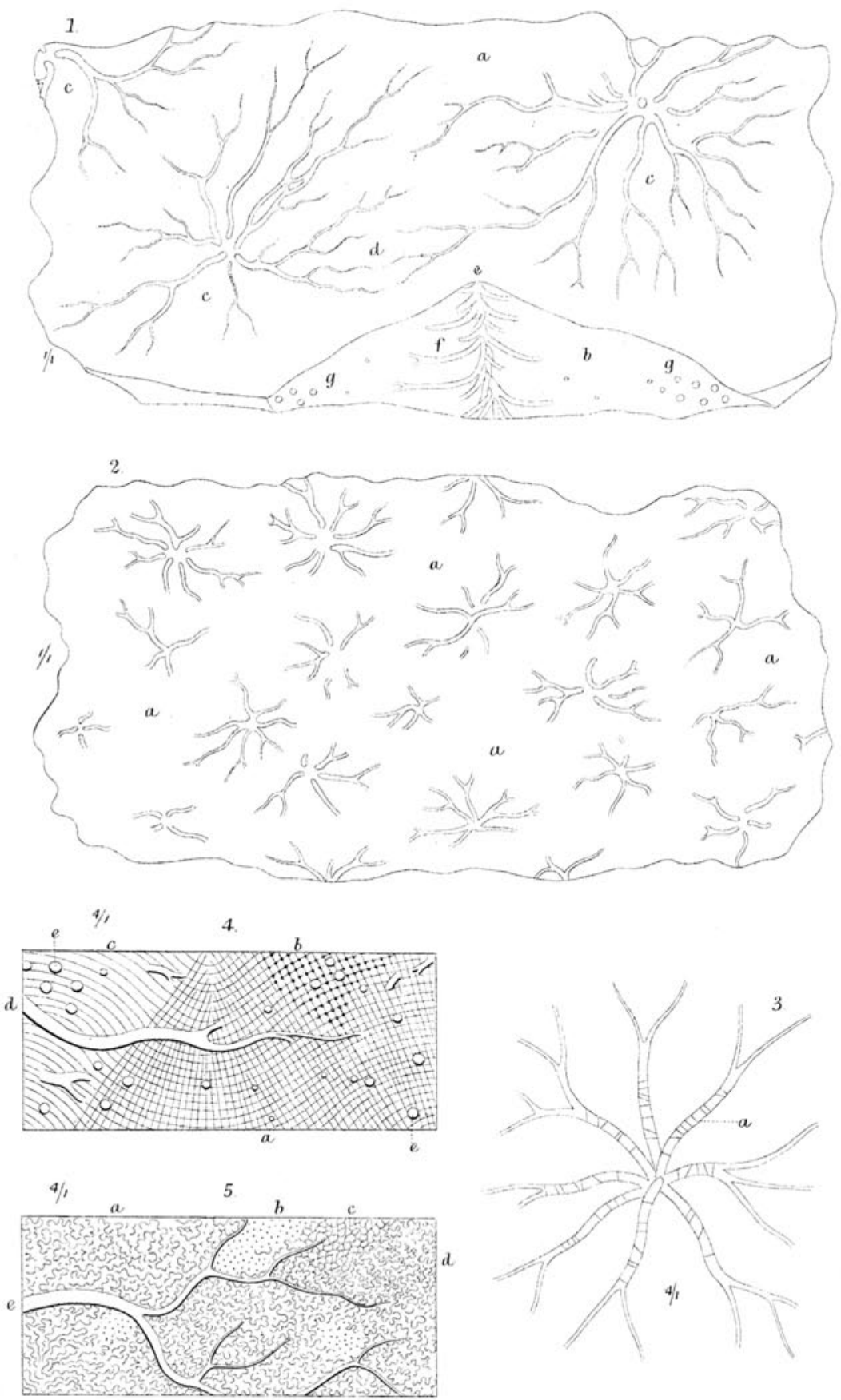
tubes have not the internal structure of Syringopora, but are hollow, and therefore cannot belong to that genus" (l. c.).

His original statement, however, best accords with the observations I made last year (before I knew what Dr. Roemer had published in 1844, 'Das Rheinische Uebergangsgebirge,' p. 57), viz. that Mr. Champernowne had shown me specimens of the so-called cyathophylloid coral (Battersbya) and Syringopora, respectiv̈ely enveloped in Stromatopora, like the tubes of the so-called Caunopora ('Annals,' vol. iv. p. 102).

Again, these "tubes," although often apparently "hollow" (from the homogeneous crystalline character of the calcspar filling them), as stated by Dr. Roemer, yet sometimes, as my specimens show, present not only infundibuliform tabulæ, like those of Syringopora, but horizontal ones like those in Millepora alcicornis, as figured in 1877 ('Annals,' vol. xix. pl. viii. figs. 21-23) - a combination in Syringolites huronensis, Hinde, to which Dr. G. Steinmann has lately called attention as "scarcely" differing from Syringopora infundibulifera, Goldf. (Neues Jahrbuch f. Mineral. Geol. u. Paläont. Jahrgang 1880, Band i. p. 435, with illustration); hence Roemer's original statement might not have been altogether wrong. Still I have one specimen from "Pit-Park Quarry" in which the Stromatopora surrounding a Cyathophylloid coral is so densely charged with Aulopora repens, var. minutula, Goldf., that it appears unmistakably, weathered out on the surface, in its genuine double branching form.

Caunopora, therefore, having been found to be no genus, but a compound of Stromatopora and Aulopora repens, renders (as I have before stated) a description of Stromatopora much more simple, which is thus reduced to the basal structure and the stellate venations, in the larger branches of which I have lately found the tabulæ which it is my object now to describe. But before doing so it is also desirable that we should first direct our attention to the nature of "tabulæ" generally, and then as they appear in the tubular spaces of that living organism which is the nearest yet found to Stromatopora, viz. Millepora alcicornis.

The term "tabulæ" has been given to those portions of the coenenchyma which traverse the tubular structure of the so-called "Tabulate Corals" (ex. gr. Favosites). They are formed pari passu with the growth of the tubes that in juxtaposition follow a concentric laminated development of the coral, which is thus made up of them, so that in a vertical section the tabulæ appear to correspond with the laminæ of 
Mr. H. J. Carter on Stromatopora dartingtoniensis. 341

the coral : but it is not so really; for on closer examination they will not only be found to be more or less inequidistant, but often more or less oblique, showing that the growing surface of the coral must have always been so far irregular or pitted; hence the tabulæ in the tube of Favosites \&c., although generally, are not always equidistant, and are often more or less oblique. This irregularity is well illustrated in Mr. Berjeau's faithful drawnings at the end of Nicholson's valuable work on the Tabulate Corals of the Palæozoic Period (Blackwood and Sons, Edinb. 1879); while sometimes they are scarcely, if at all, distinguishable from the rest of the homogeneous transparent calcspar which fills the tube. It is necessary to remember all this; for it will tend to explain what may hereafter be stated of the tabulation in the "stellate venation," or astrorhiza, of Stromatopora, viz. the irregular disposition of the tabulæ as regards distance, direction, and definition, they being sometimes, although present, undistinguishable from the rest of the calcspar filling the tubes.

Astrorhiza.-In my paper "on the Structure of Stromatopora" ("Annals,' 1879, vol. iv. p. 258) I have described the stelliform parts of the conosarcal cavities under the head of "stellate venation;" but this term is not sufficiently expressive for the defined and characteristic feature which this part of the cœenosarcal structure generally presents; hence I shall hereafter substitute for it "astrorhiza," as fulfilling the purpose better, at the same time that it is more in accordance with the term "hydrorhiza," already applied to the root-like or originating portion of Hydroid Zoophytes; for the astrorhiza, according to my view, is homologous with the "stolon-like tubulation," which is put forth from the embryo of Hydractinia echinata for the development of the individual, whose horny structure or cœnenchyma is formed upon a filament of the same kind of coenosarc as that which pari passu covers its exterior and produces the polypites ('Annals,' 1877, vol. xix. p. 46 , pl. viii. fig. $3 c$, \&c.), whereby the astrorhiza becomes in plurality (Pl. XVIII. fig. 2, a a a) the origin of each lamina of the Stromatopora, through which the whole mass is finally produced.

Those who have read Mr. H. N. Moseley's admirable paper "On the Structure of Millepora" \&c. (Phil. Tran's. 1877, vol. clxvii. pt. 1, p. 117) must have observed (at p. 125) that he uses the term "hydrophyton" for the whole of the conosare in Mitlepora as "homologous with the hydrorhiza of other hydroids ;" but inasmuch as Mr. Moseley finds it necessary afterwards to make a distinction between the "main canals" and the smaller ramifying ones which con- 
tain the basal or vermicular cœenosare of Millepora, so in Stromatopora it becomes necessary to make a similar distinction; but the "main canals" here assuming for the most part a stellate form, in which the branches radiate from fixed points in the laminæ successively, instead of meandering about irregularly as in Millepora, I propose henceforth to designate each group by the name of "astrorhiza," as above mentioned (Pl. XVIII. fig. 1,ccc). At the same time it should be remembered that, although the astrorhiza is so strongly developed in Stromatopora dartingtoniensis, there are other species in which it is so little differentiated from the general coenosarcal structure that none but an experienced eye can detect its presence.

What, then, is the condition of the tabula in Millepora alcicornis (which so far may be considered the nearest living representative of Stromatopora)? Here they present themselves in the way above mentioned, in the tubular spaces extending from the axial structure of the branch through its cœnenchymal tissue to the circumference. I have said "spaces;" for the conosarc, from its extreme tenuity, almost wholly disappears on desiccation, when the tube itself is left as a mere excavation without wall in the midst of the coenenchymal tissue; hence the cœnosarc of the latter is continuous with that which originally filled these tubular spaces, and but for the presence of the tabulæ, which act like so many diaphragms in dividing the space into separate compartments, the coenosare in them would be directly continuous throughout. In structure, composition, and size the tabulæ (often, however, provided with a stelliform prolongation outwardly, as in Tubipora musica) are thin imperforate plates of calcspar, about 1-1800th inch thick, and, on an average, about 1-120th inch apart. Here, again, it is necessary to remember that the conosarcal cavities, which are vermiculate, open into the "tubular space" throughout, and therefore that the cœnosare which originally filled the tubular spaces was continuous with the cœenosarc which filled the coenosarcal cavities or vermicular channels of the conenchyma.

Thus we are prepared to follow out my description of the tabulation in the larger branches of the astrorhiza in Stromatopora, which I have no doubt will be received with much hesitation; but if I can show that, under certain circumstances, these tabulæ are left in the branches of the astrorhiza as they appear in the tubular spaces of Millepora, while all the rest of the calcspar has been removed, and that they are also to be scen in the midst of the calcspar filling the branches 
Mr. H. J. Carter on Stromatopora dartingtoniensis. 343

of the astrorhiza in the more consolidated fossil, I do not see how we can come to any other conclusion than that, although the tabulation is not so evident or striking as that of Favosites \&c., it nevertheless, under certain conditions, makes its appearance here and there in the large branches of the astrorhiza,-which is quite sufficient for our considering Stromatopora to have been a "tabulate coral."

As announced in the last number of the "Annals,' I, on the 26th July last, under the kind guidance of my friend, Mr. Champernowne, F.G.S., again visited "Pit-Park Quarry" (which is in the Devonian Limestone near his residence at Dartington Hall, Totnes), in quest of the species of Stromatopora to which I have before alluded as possessing the largest development of the astrorhiza ("stellate venation") that has been problished. This in due time we came upon; and splitting oft' some portions from the block, a fracture passed horizontally through the plane of lamination so as to divide a set of astrorhizæ also horizontally, and almost equally, so that they were visible on each surface of the fracture. It was observed, too, that they were more marked than usual, owing to a partial decomposition and removal of their contents, which rendered the branches more or less empty and of a light brown colour; but having no time then to examine them more particularly, the specimens were put aside until I came home (Pl. XVIII. fig. $2, a a a)$.

Returning, then, to the examination of this specimen at the beginning of August, I observed that not only had the contents of the branches of the astrorhiza been partially removed by decomposition, but in the greater number of the larger branches thin diaphragms of calcspar had been left, which, although a little more irregular in disposition and direction, presented the same appearance as the tabulæ in Millepora alcicornis, and about the same thickness, viz. 1-1800th inch (Pl. XVIII. fig. 3). Impressed, therefore, with this fact, yet not observing the plates in the calcspar filling the branches of the astrorhizæ in other parts where it had not been removed by decomposition, I sought for it in more consolidated specimens of other Stromatoporce, wherein I felt convinced that I had seen something of the kind. So I repaired to Mr. Vicary's large collection of polished slices at Exeter, to which I have before alluded; and showing him a fragment of the specimen from "Pit-Park Quarry" which presented the fabulated appearance above mentioned, he immediately and of his own accord picked out three different species in which it was unquestionably illustrated, observing that "when one knows what to look for, it is not difficult to find it." This comparatively 


\section{Mr. H. J. Carter on Stromatopora dartingtoniensis.}

independent evidence was of course more acceptable than if I had selected the specimens myself. I afterwards found, on polishing another specimen of a species of Stromatopora with curvilinear structure, that I had brought away from "Pit-Park Quarry" a much better illustration of it than in any other of a like kind.

Here it is necessary to state that, in all probability, the finding of a specimen of Stromatopora in which the calcspar usually filling the branches of the astrorhiza has been removed by decomposition, and the tabulæ left, is very rare, and that, even when it is found, the branches for the most part, not running along on the same plane, may only be partially exposed here and there in the horizontal section, so as to present but a few of the tabulæ with which they may be more or less traversed throughout. Then the irregular disposition of tabulæ, both as to distance and direction, is rather the rule than the exception, as may be seen by the illustrations of the "Tabulate Corals" at the end of Prof. Nicholson's magnificent book, to which I have before alluded; while the impossibility of distinguishing the tabulæ from the general mass of transparent calcspar with which the branches of the astrorhiza are usually filled, is illustrated by a similar occurrence sometimes even in Favosites, where they are generally so well marked.

When, however, we recur to the slices of more consolidated Stromatopore which are polished over the lamination, this tabulated structure in the branches of the astrorhiza is not so uncommon, if we know what to look for; but as, in Millepora, the astrorhizal venation of Stromatopora is, as it were, excavated in the conenchymal structure without wall, and the vermiculate channels of the coenosarc freely open into the cavity of the branch, so in the horizontal section, which barely touches the branch, a number of holes may be observed along its course; but the fibre separating these must not be confounded with the tabulæ, nor must the extension of the cœnenchymal structure or filament across the branch be confounded with them; but we must look for a specimen in which the plane of the section has fairly taken off the whole of the surface of the branch, and then seek for white lines which traverse it directly (that is, without curvature) and not in continuation with the fibre of the coenchyma, when there will be little left for us to conclude than that such a structure must be owing to tabulation.

Although the fact may not bear directly upon the argument in favour of tabulation in Stromatopora, yet it may be observed that all the corals in the "quarry," which are more or 
less enveloped in the Stromatoporce, possess the tabulated character, so that if Stromatopora did not do so it would be an exception. Nor must it be fancied that the tabulæ in Stromatopora and Millepora are totally different from what occurs generally in that family of the Hydroids to which $I$ have likened the former. On the contrary they do occur, although in a modified form, in the Hydractiniidæ and in the annular constrictions of the flexible Hydroids, as $\mathrm{I}$ have already shown (Ann. \& Mag. Nat. Hist. 1877, vol. xix. pl. viii. fig. $4, g g$, and figs. 9 and 12).

Having thus described the tabulation in Stromatopora, let us now direct our attention to that species in which it first presented itself to my notice, since the astrorhiza here, in some instances, far exceeds in size the largest given by Baron Rosen, viz. that in Stromatopora astroites ('Natur der Stromatoporen,' Taf. ii. fig. 6 ; and 'Annals,' 1879, vol. iv. pl. xv. fig. 1); so it is just possible that the Dartington species may not have been publicly noticed, and hence it is desirable to give its principal features, so far as they are at our command; but before doing so it will be as well to recall to mind what I stated and illustrated respecting the division of the cœnenchymal structure of the Stromatoporce into "rectilinear and curvilinear," viz. that of course this was "subject to modifications which more particularly belong to the description of the species respectively" ("Annals,' 1879, vol. iv. p. 254). These "modifications" consist of the passage of one kind of structure into the other, so that the species in this respect may be more allied to the former than to the latter, and vice versô. There is also a difficulty in getting the real or original surface of the species, chiefly on account of weathering and decomposition, whereby a most important distinction may be lost; while the general form may be influenced by that of the organism orer which the Stromatopora may have grown (ex. gr. a branched coral)-just as at the present day a number of specimens of calcareous Polyzoa dredged in Bass's Strait for the Liverpool Free Museum, by Capt. Cawne Warren, have been found to derive their varied form from that of different kinds of sponges which they have overgrown. Hence it again becomes difficult to determine what the original form of a Stromatopora was, further than that, when not influenced in the way mentioned, it assumes a massive state of concentric lamination like that of any other coral of a like growth, exceeding sometimes two or three feet in diameter. Following is a description of what we know of the Dartington species:-

Ann. \& Mag. N. Hist. Ser. 5. Vol. vi. 
346 Mr. H. J. Carter on Stromatopora dartingtoniensis.

\section{Stromatopora dartingtoniensis, n. sp. \\ (Pl. XVIII. figs. 1-5.)}

Coral massive (Pl. XVIII. fig. 2) or spreading over foreign objects (fig. 1); the latter form presenting a reticulated surface which is more or less grooved throughout by branches of the astrorhiza, that radiate respectively from more or less convex elevations, whose summits, from weathering, may present one or more apertures (fig. $1, c c c$ ); mutatis mutandis, like the growing surfaces of Millepora alcicornis and Hydractinia arborescens, \&c. Showing in the vertical section (fig. 4) that the basal structure or cenenchyma is composed of rectilinear latticework, arranged in concentric, more or less undulating laminæ, traversed by the branches of the astrorhiza (fig. 4, d,ee); and in the horizontal section (fig. 5) a union of the ends of the perpendicular rods by intervening fibre, which presents a curvilinear or quasi-vermicular form, still traversed by the branches of the astrorhiza, but now seen from a horizontal point of view instead of laterally, whereby the branch is more or less observed to ramify among the coenenchyma (fig. $5, e$ ), until, by subdivision, it finally becomes confluent with the vermiculated conosarcal canaliculi, with which, too, it is also in communication laterally throughout its whole course. Astrorhiza consisting of a group of radiating branches, which dip downwards from a vertical axis to ramify on all sides among the laminated coenenchyma until they are lost by subdivision in the canaliculi of the conosarc, as just stated (fig. 1, $c c c$ and $b, e, g g$, also fig. $4, d$, and fig. $5, e, \& c$.$) ; parting from the axis succes-$ sively (fig. 1,e,f) stolon-like, without any distinctly continuous vertical canal or stem; the larger branches traversed here and there by tabulæ, inequidistant, direct or oblique (fig. $3, a$ ). Centres of the astrorhizie at different distances from each other, varying from $\frac{1}{2}-1$ inch in the massive form (fig. 2, $a a a a$ ), but much wider apart in the incrusting one (fig. 1, ccc), where the branches are sometimes 2 inches long and 1-24th inch wide near the centre. Size variable.

Hab. Marine.

Loc. Devonian Limestone. Pit-Park Quarry, Dartington, near Totnes.

Obs. It is not improbable that fig. 1 represents the true surface of the incrusting form, but so altered by weathering and decomposition that it presents nothing satisfactory beyond the large size of the astrorhizæ; while in fig. 2 the branches of the astrorhize are necessarily represented as truncate, from their ultimate ramifications being below the plane of fracture. In the vertical section of the coenenchyma (fig. 4) the lines of 
fibre are all inflated at their point of contact, as shown at fig. $4, b$; and on account of the undulating development of the lamine the horizontal section (fig. 5), although generally presenting the curvilinear structure (fig. $5, a$ ), sometimes presents a punctate one (fig. $5, b$ ), or a retiform one, as at fig. $5, c$, or a more compact curvilinear one, as at fig. $5, d, \&$ c. \&c., owing to the section passing through the undulations at slightly variable depths.

Of course the above description of $S$. dartingtonionsis, having been taken from only a few specimens of the species found in "Pit-Park Quarry," must be considered approximative, since it probably not only exists throughout the Devonian Limestone of the neighbourhood, but may be found to present itself under many more forms, both generally and structurally, than those above mentioned.

\section{EXPLANATION OF PLATE XVIII.}

Fig. 1. Stromatopora dartingtoniensis, n. sp. Natural size. Incrusting form, showing:- $a$, natural surface; $b$, broken surface; $c c c$, astrorhizæ; $d$, union of ultimate branches of the astrorhizæ ; $e$, vertical section of the astrorhiza as it is developed upwards through the structure of the Stromatopor $a$; $f$, ends of the branches obliquely cut by the section; $g g$, truncated ends of branches of the astrorhizæ as they appear in a vertical section of Stromatopora.

Fig. 2. The same. Natural size. Massive form. Tracing of the plane of fracture $a$ a $a$ a, showing the form, size, and arrangement of the astrorhize, whose branches are partially empty, all the calcopar but the tabulæ having been remored by ? decomposition.

N.B. As the branches of the astrorhizæ are not on the same plane, but generally dip downwards (fig. $1, f$ ), their smaller branches disn ppear in the horizontal section, and thus the larger ones look in the delineation as if abruptly terminated.

Fig. 3. The same. Astrorhiza of fig. 2, magnified about four diameters, to show $a$, the tabulæ. Diagram.

Fig. 4. The same. Vertical section, to show the structure of the coenenchyma, relatively magnilied about four diameters. a, appearance of the vertical rods and horizontal lines of the lamina as they cross each other st nearly right angles, modified by slight undulations; $b$, portion shuwing their inflation at the point of intersection; $c$, portion in which the vertical rods are omitted and the lines of the laminæ only inserted; $d$, large branch of an astrorhiza; $e$ e, truncated branches of astrorhiza as they appear in the vertical section. Diagram.

Fig. 5. The same. Horizontal section, to show the structure of the conenchyma, relatively magnified about four diameters. a, curvilinear appearance of the lines of the lamina when viewed horizontally-sometimes, owing to the undulation of the lamina, presenting a punctate appearance $(b)$, or a reticulated one $(c)$, or a more compact curvilinear structure $(d) ; e$, branch of astrorhiza. Diagram. 